\title{
A Study of the Current Situation and Countermeasures of Medical English Talents Training Based on KAQ Education Mode*
}

\author{
Yuan Kong \\ School of Foreign Languages, Jining Medical University, Jining, China
}

\begin{abstract}
In order to cope with the challenge of medical English education, based on reading and researching related data in English Majors in medical colleges and analysis of the current situation of English training in medical colleges in China, this paper explores the medical English specialty cultivation mode, and provide a theoretical reference for the relevant departments to implement education reform. Through the actual investigation, a medical college is compared with other professional medical college English curriculum education system, training system and student satisfaction and opinions on the stage in order to explore the status of English medical personnel professional training. Then, it puts forward the integration methods of medical English training and advice of KAQ model. The aim is to provide theoretical basis and practical guidance for the training of medical English professionals with comprehensive development of knowledge, ability and quality.
\end{abstract}

Index Terms - medical English, KAQ education mode, current situation of talents training, countermeasures

\section{INTRODUCTION}

The current countries have established closer ties in all aspects of the global integration of economy, education and culture. In recent years, with the continuous improvement of China's comprehensive national strength, there is an increasing number of academic exchanges with foreign medical fields. In the medical system, medical and health departments, pharmaceutical enterprises and related units all need compound talents who are proficient in both English and medical knowledge. Medical English professionals are one of the important ways to promote academic exchange in international medical field, and play a vital role in further strengthening the development of medical field in China. Therefore, it is very important to explore and cultivate high-quality medical English professionals in medical colleges. At present, many medical colleges in China have set the direction of medical English majors. we have obtained certain achievements, but generally speaking, the medical English Teaching in China are not perfect, the degree of attention in the school, the design of textbook, teaching mode and the development of teachers and other factors restrict the medical English teaching and can not meet the employers' demands. In order to achieve the goal of training comprehensive medical talents, universities have made efforts in all aspects, especially in curriculum design, seeking various theoretical supports, including ESP (English for Specific Purposes) teaching theory and so on. Although medical English teaching is faced with many difficulties and limitations, we can still achieve the goal of medical English teaching by integrating teaching resources, developing teaching ideas and exploring students' self- learning potential.

\section{Definition OF THE Related CONCEPTS}

\section{A. KAQ Personnel Training Mode}

KAQ talent cultivation mode is produced in the big background of contemporary educational reform. KAQ mode is the comprehensive training model of "Knowledge, Ability and Quality". Knowledge, ability and quality are three complementary and inseparable. Knowledge is the development of talents. It is an effective carrier of ability and quality, including scientific and cultural knowledge, professional basic knowledge and professional knowledge, and knowledge of adjacent disciplines. The acquisition of ability is based on a certain amount of knowledge and practical training as the main training means, including the ability to acquire knowledge, the ability to use knowledge and the ability of innovation. Quality is the whole reflection of thinking and behavior, a comprehensive reflection of knowledge, ability and quality of sentiment, mainly through the understanding and practice of the individual, the acquisition of knowledge,

\footnotetext{
* Funding Sources: Social Science Planning Research Program of Shandong Province (Grant No. 17CWZJ38); Scientific Research Program of Colleges and Universities in Shandong Province (Grant No. J17RA054); Research Program of Young Teachers' Education and Teaching of Shandong Province (Grant No. 16SDJ232); Key Program in Art Science of Shandong Province (Grant No. ZX2015005); Youth and Adolescents Quality Education Work Planning Program of Shandong Province (Grant No. 13AJY090); Scientific Research Program of Jining Medical University (Grant No. JY2013RW032); The Visiting Scholar Funded Program of Young Backbone Teachers in Jining Medical University; College Students' Innovative Training Project of Jining Medical University (Grant No. cx2017052); Scientific Research Project of College Students in Jining Medical University (Grant No. JYXS2017RW017)
} 
ability and internalization of people's mind, the formation of sublimation of quality and accomplishment more stable to promote the expansion of knowledge and ability and enhance.

The practice has proved that KAQ application of personnel training mode is to develop a solid foundation, wide vision, has certain innovation ability and comprehensive ability, but also have high quality. KAQ is not only applied to medical and health information management specialty, but also widely applied in other professional talents training. Facts show that KAQ application talents training is successful.

\section{B. Medical English Majors}

Medical English major is medical and English mixing, medical English specialty refers to "on medical English Majors" medicine and English context is the professional qualities, the training objectives of the compound is medicine and the knowledge and skills of English. English Majors in medical colleges and universities are important ways to promote academic exchanges in the international field of medicine, and play a vital role in further strengthening the development of domestic medicine. It is urgent to train high-quality medical English professionals. Many medical schools have set up English Majors in medical direction, aiming at training compound talents of "English + medical + X", adapting to the trend of international medical modernization, and meeting the trend of higher education. The medical English major has two notable characteristics: practicality and professionalism. The medical English compound talents that the society needs should have the knowledge of medical and English teaching, strong practical ability and high comprehensive ability.

\section{SOURCES AND METHODS OF RESEARCH}

\section{A. Source of Information and Data}

The curricula and training methods of various medical colleges and universities are derived from the official websites of various schools and related network platforms.

Questionnaires were used to investigate the degree of satisfaction of the current education mode and the training of medical English professionals by e-mail or on-site distribution.

The interview data came from the teaching teachers and the students work management teachers of the Foreign Language College of a medical university.

\section{B. Research Methods}

The survey was conducted mainly through field investigation and e-mail. A student contacted with a Foreign Language College of a medical college was sent a questionnaire through e-mail. The questionnaire was collected for a week. A total of 100 copies of paper and web questionnaires were collected, and the data were preprocessed. Then, EpiData3.1 software was used to build and store data. Finally, SPSS17.0 software was used for statistical analysis.

This interview is a course teacher and student management teacher in a Foreign Medical School of a Medical University, including English teaching and research section teachers, medical English teaching and research section teachers, and students work management teachers.

\section{InVestigation Result And Discussion of the Present Situation}

\section{A. Medical College English Major Curriculum and Educational Model Comparison}

This study collected information on the curriculum of English majors and the training mode of talents in several foreign language colleges of medical universities.

The following conclusions are made by comparing the training objectives and employment direction of several colleges and universities. First, when training medical professional English talents, all medical schools aim to cultivate compound talents with both English professional ability and medical professional ability. Second, some medical colleges and universities pay attention to the training of English ability, grant the degree of literature, and some pay attention to the cultivation of medical professional ability. Third, from the direction of employment after graduation, some school employment areas tend to be more medical institutions, while other medical English majors have similar employment orientation with language majors. This shows that the specialty of medical English is not distinct, and there is no obvious difference to the training mode of the conventional English major. Fourth, according to the social demands and the talent of its own development characteristics, some training objectives are in line with the concept of the cultivation of medical talents of English. However, because of college teachers, curriculum systems and teaching organizations and teaching methods such as uneven levels of development, they seriously restrict the development of the concept of culture.

According to the investigation of the English major courses in several medical colleges and universities, the following conclusions can be drawn. First, in the course setting of medical colleges, English majors account for the largest proportion. Second, in some colleges and universities, the proportion of comprehensive quality courses in all courses is second to the English major courses. Third, the basic medical courses of most medical colleges and universities are less than $15 \%$. Fourth, some medical colleges and universities set up a small number of practical courses, and some colleges and universities are not set up. Fifth, in the course of curriculum, there is a general problem 
of imperfect curriculum system and the disproportions of the proportion of English and medical courses.

\section{B. Questionnaire Survey}

1. Basic situation of the students investigated

In order to better understand the students' perception of the process for medical English education, this study through the on-site questionnaire and network questionnaire investigated the College English Majors in a medical (Medical English direction) students in the school and the graduate students of a total of 100 people (not chose the Junior a reason is its unfinished curriculum, can't give a comprehensive evaluation).Among them, $61.86 \%$ are girls and $38.14 \%$ are boys.

2. Analysis of results of the survey

a. The degree of satisfaction of medical English students to knowledge training

The survey shows that the degree of knowledge acquisition satisfaction is more consistent with the high and low ratio of curriculum setting. First of all, in a Medical University, the satisfaction in Medical English students for English Majors (Medical English direction) are common $(<59 \%)$, the proportion of the degree of satisfaction with the setting of professional courses shows consistent characteristics. Generally speaking, knowledge acquisition still needs to be strengthened. Secondly, the satisfaction degree of the comprehensive quality courses is the highest (> 81\%), which is closely related to the higher proportion of the comprehensive quality course of foreign language majors in a medical university. Again, the basic medical courses' satisfaction is relatively low $(<38 \%)$, a medical university has fewer courses on the related knowledge of medicine, including the introduction of basic medicine, clinical medicine course, only accounted for $5.32 \%$ of the total hours; a small number of courses will inevitably lead to that medical professional knowledge teaching is only limited to the basic knowledge of rough and plain, not involving technical skills. In addition, a foreign language specialty in a medical university did not set up practical courses. Through understanding, we know that there are a few practice opportunities in the learning stage, such as paid internships in the US, but they are not systematically planned, and the low degree of students' participation leads to their lowest satisfaction $(<14 \%)$. Finally, in terms of knowledge acquisition satisfaction, men and women show a same trend in general. To sum up, in the field of knowledge acquisition, especially medical and practice courses need to be increased.

b. The degree of satisfaction of medical English students to train ability

The survey found that through four years of study, it is common to develop a strong English ability, the degree of satisfaction is the highest $(>83 \%)$. But the medical professional ability is poor, the degree of satisfaction is the lowest $(<12 \%)$, the results which compare with the conventional English Majors (Language) has no advantage, and also reflects the problem that current curriculum system is unreasonable. Secondly, the degree of satisfaction of organization ability (>51\%), the degree of satisfaction of communication (> 67\%), which means that the current training mode for students' organizational communication ability is greatly improved, especially rich activities in the second classroom, such as the English Drama Festival, it has greatly promoted the ability of organization and communication. Again, the satisfaction of innovation ability $(<36 \%)$, strain capacity satisfaction $(<16 \%)$, which is related to the lack of professional practice courses, the training of strain capacity and innovation ability is not enough, the ability of practice needs to be improved, men and women show a same a trend roughly.

c. The degree of satisfaction of medical English students to quality training

The survey found that through the current training mode, the students' recognition for these qualities is stronger, and the moral quality is the highest among them (> 90\%). Secondly, responsibility satisfaction (> 82\%), the collective sense of honor (>77\%), which is closely related to the rich activities in second classroom, such as English Drama Festival, New Year party, English corner and English speech contest, through participation in the activities, the collective sense of honor and responsibility has been greatly improved. Thirdly, the lowest degree of initiative satisfaction $(<51 \%)$, especially for girls, who think their aggressive mind need to be promoted accounts for $58.14 \%$, which means that students in this field generally have low competitive consciousness. Finally, and there were significant differences in the two aspects of cooperation consciousness and positive psychological adjustment, the boys have a higher sense of cooperation, the girls have better psychological adjustment quality, which is closely related with the physiological and psychological differences between men and women. It also shows that promotion of the comprehensive quality is very large.

d. The expectation and suggestions of medical English students to the existing training methods

Through to the senior school students for the future direction of the employment expectations, the evaluation of work in current situation from the graduates, we found that the number of graduated English students who engaged in medical professionals from a medical university is rare, employment units mostly are secretarial, translation, tourism management, etc.. And senior students in the school currently are in the process of employment. According to the employment situation, the target unit and the actual employment units are different, many students targeted employment units are medical institutions, because of its medical professional skills is not strong, resulting in the final choices are non medical establishments. Most students mentioned less medical courses (Cheng \& Zheng, 2012).They hope that the school can optimize the curriculum and deal well with the relationship between medical courses and English courses, so as to promote students' comprehensive training of knowledge, ability and quality. In addition, the practice base without professional counterpart is a common concern for students.

According to a survey of English students in a Medical University, we can draw the following conclusions: first, the 
acquisition of English knowledge is better, through four years of study, they reserved a solid knowledge of the English language, and developed a strong professional English ability, but the lack of medical courses, which leaded to professional medical knowledge and medical knowledge ability is obviously insufficient. The acquisition of medical knowledge also needs to be improved. Second, the major does not open the practice course (Li, 2014). There is no practice base, graduation practice requirements and participation is uneven, resulting in students' practical ability, especially strain capacity and innovation ability is generally low. Third, after four years of study, a better comprehensive quality has been trained, but there is a lot of room for promotion in the sense of cooperation and positive psychological adjustment. Fourth, due to the lack of medical knowledge, there is a big difference between students' employment expectations and practical work. Graduates rarely engage in medical and health systems, and employment units are roughly the same as regular language majors, without obvious competitive advantages.

\section{Personal Interview Results}

The object of this interview was the medical English major of a Medical University, the teacher of the English course, the teacher of the medical course and the management teacher of the student. The main content of the interview is aimed at the training objectives, teaching methods, training methods, curriculum settings and training programs of medical English majors.

The interview found that several teachers were basically consistent with the current educational methods and the knowledge of medical English professionals. Some valuable suggestions are given in the current education scheme, the training mode and the course setting of colleges to universities. Firstly, we should strengthen the construction of teaching staff so as to improve students' satisfaction with teachers' teaching and evaluate their teaching ability, so as to enhance their interest in learning and improve their teaching quality. Secondly, we should enrich the way of teaching, increase theory and practice teaching curriculum proportion, teaching knowledge is not confined to the textbooks, not limited to "the teachers speak, the students listen" mode, improving students' enthusiasm and participation, strengthen the teacher-student interaction, such as let students go to explain their point of view and changing the roles between teachers and students etc. Thirdly, we should enrich the way of examination and lay stress on the training of students' practical ability and comprehensive quality. Besides the traditional closed examination method, we should conduct examinations in various ways, including curriculum assignments, speeches and exhibitions, and practical operations. Fourthly, in terms of curriculum design, the proportion of English curriculum system and medical curriculum system is incompatible. The lack of medical knowledge can not achieve the goal of compound talents who master both English knowledge and medical knowledge. We should highlight the characteristics of medical English and increase medical courses. Fifthly, they think that the construction of practice base is very important, through internships, students from the campus learners gradually transformed into a social participant. It is an important way to transform book knowledge into social practice ability; it is an important part of internalizing knowledge, strengthening ability and improving quality; it is essential for the cultivation of students' knowledge, ability and quality (Li \& Xu, 2015).

\section{KAQ-BAsed Training Program for Medical English Majors}

\section{A. To Make Clear the Goal of Training}

In the process of training talents, the purpose of professional training is the role of the compass. Through the preliminary investigation and the employment situation in other units, from the current medical English Majors' employment intention, we found that who desire to engage with the medical and related work is of the higher proportion of graduates, but from the graduated situation, the direction of most of the graduates and the conventional English majors is similar, a few graduates engaged in other occupation, such as pharmaceutical sales representatives, civil servants and so on (Liu \& Li, 2013). There is still a certain gap between the intention of employment and the actual employment situation. Therefore, in order to enable students to survive in a highly competitive market, schools must understand the needs of society and students' needs, and rationally adjust their training objectives.

As the key factor in the process of talent training, the training goal of the professional needs is to be formulated according to the characteristics of the University, the social needs, the quality of the source and so on. The goal of developing medical English talents is to clarify or solve the problem of attribute of medical English. It belongs to the humanities, namely, English major (medical direction), or medical science, or medical English. The quality of the subject will help the major to make a clear direction in the professional content and the focus of training. At the same time, only $25(50 \%)$ of the 50 medical colleges and universities set up medical English majors were targeted at the training of compound talents, and most of the training objective of most colleges and universities were singled out as application oriented and academic or target unclear. On the one hand, it shows that there are some deviations in training objectives of some medical schools in China, which may be related to the late start of professional construction. On the other hand, it shows that some medical schools do not pay enough attention to the goal of talent training. Medical English majors in Chinese medical colleges and universities as interdisciplinary majors, the goal of training talents is different from that of the regular English and medical majors, mainly reflected in the basic ideological and moral quality, solid English basic skills, strong application ability of English major medical knowledge and physical and mental health of five aspects (Ma, 2011).

Therefore, after extensive and detailed investigation and research, combined with the KAQ model, the talent training 
objective of medical English, we should train the students who adapt to China's socialist modernization, with strong comprehensive ability of English and medical knowledge, more comprehensive and more humanistic literacy, in education and scientific research, health and other departments engaged in translation, research, teaching and management. The training contents of the professional specialized research include medical knowledge and skills of English language training in English, solid knowledge, basic medicine, clinical medicine, computer science and other knowledge, skilled use of English in the field of medicine and medical science research work.

\section{B. To Optimize the Curriculum System and Build Professional Features}

1. Characteristics of specialty course

The curriculum should highlight its characteristics. The general trend of development is to connect with the reform of the national medical English Major Curriculum Model, in order to adapt to the social needs of the quality of medical English talents, to meet the need of market employment, to set up a course setting model suitable for and conforming to the goal and orientation of the training of the school talents. According to the two characteristics of the medical English specialty, which is practical and professional, the professional features should be highlighted during the course setting and teaching process. According to the current needs of society for talents of medical English, in strengthening the cultivation of English application ability and professional curriculum setting has interdisciplinary characteristics, medical, social and cultural knowledge into English teaching system, such as setting up medical literature retrieval, medical English translation, medical English writing, medical English reading courses, enhance the students' comprehensive quality and practical ability. At the same time, we can also set up relevant practice projects according to student interest, expand students' related professional knowledge, stimulate students' autonomous learning, and promote students' personalized learning. It will lead the students to find a new way of understanding medicine in the English language context, and improve the practical application ability of listening, speaking, reading, writing and translation in the field of medical English (Mou \& Zhang, 2013).

2. Rationalization of curriculum system

Medical English is derived from ESP. As a branch of ESP, medical English courses reflect the integration of English and medicine and have strong professional attributes. Therefore, only when the curriculum is optimally optimized, can students achieve effective learning goals in a limited time, so as to cultivate talents who are proficient in both English and medicine. English curriculum should contain English listening and speaking, reading and writing in four aspects of professional skills courses and professional knowledge of English curriculum, emphasize the mastery of English skills. Medical courses include basic medical knowledge and emphasize women and children inside and outside, and lay a solid foundation of medical knowledge. Medical English courses include medical English translation, medical English writing, English reading training courses, emphasizing on medical knowledge of English proficiency (Wang, 2014). Quality courses are mainly for public courses in the humanities and Social Sciences, cultivating students' comprehensive quality. In the teaching process, pay attention to the basic English ability of low grade to start training, to gradually improve the cultivation of medical English and mutual penetration ability, in the professional curriculum should highlight the ability to use English language, but also to strengthen students' basic medical knowledge. Ultimately, students will have good intercultural communicative competence, medical literature reading ability, medical translation ability and medical oral communication ability, which is the training content of specialized courses. We should train talents with solid English language and basic knowledge and skills in medical English. In addition, medical related limited elective courses can be offered. By studying these courses, students can master and understand basic medical knowledge, meanwhile, strengthen the practical application ability of English language in medicine, and improve their knowledge structure.

3. Individualization of elective course

Nowadays, the system of credit system, which takes the elective system as the core, is widely used in the professional curriculum of colleges and universities, with flexible learning time and selective selection of course contents (Wang \& $\mathrm{Ni}, 2012$ ). On the basis of ensuring professional required courses, students combine their own understanding and interest, willingness to chose courses. Elective courses are actually personalized courses for each student. Too many required courses, the students themselves want to learn or expand the relevant professional knowledge of the opportunity or time and energy is not enough, the students to be trained. In order to deepen and expand students' academic foundation, professional knowledge and related knowledge, to expand and deepen the students' professional knowledge, meet the students' personality development, hobbies, specialty training, school should have various types elective courses, at the same time in the teaching plan properly increase the proportion of elective courses to students. Such as the creation of about Social Sciences, humanities, natural science and other types of courses, the sciences and humanities, interdisciplinary elective courses showing the characteristics of multi subjects and interactivity, optimize their knowledge structure, broaden the students' professional knowledge, stimulate students' innovation consciousness, cultivate talents.

\section{To Reform the Teaching Mode and Improve the Quality of Teaching}

1. To strengthen the construction of teachers

The introduction of high-level talents is one of the main ways to build up teaching staff. Especially in high-level medical education and research institutions abroad, they have solid English knowledge and medical knowledge. It can 
play an immediate role in the teaching, medical and scientific research of the imported units. Colleges and universities can introduce high-level talents as an important means to strengthen the construction of teaching staff, expand the scale of talents, improve the overall quality of talents and optimize the structure of talent team. The introduction of talent to adhere to introduce the principles should be based on the discipline construction and personnel training, taking into account the status of the teaching staff structure and development planning, focusing on the needs of multi-level, making the introduction of talent system and preferential policies, broaden the channels for the introduction, the introduction of strict mark, vigorously the introduction of all kinds of talent shortage discipline. For the talents introduced, we should provide a good environment for their work and life in the unit and give full play to the role of talents (Zhang \& Zhao, 2014). At the same time, using the rich experience of these high level talents in scientific research and teaching, we will gradually promote the development of the original teaching staff.

To strengthen the construction of teaching staff, we should pay attention to synchronizing the introduction of talents with their own talents training. We should attach importance to the introduction of high-level talents, give full play to the role of the imported talents, and also emphasize the training of their own talents, so as to fully mobilize the enthusiasm of their talents. Therefore, medical colleges and universities should transform the medical English teachers from the following aspects to the compound medical English teachers as soon as possible. One is to adopt the method of self-cultivation and carry out the system of inner school training. Universities can send in medical teaching experience, has the solid medical knowledge background of teachers on the teaching of basic English teachers of this school are appropriate training to enable them to master some basic knowledge of medical professional as soon as possible, but also can be related to the ability of English training for medical teachers, improve their professional English ability. In addition, we should pay attention to cultivate young teachers, encourage medical colleges for undergraduate clinical medicine professional and good at English medical students studying for a master's degree in English major of medicine, provides effective way to solve the medical English teachers lean phenomenon. The second is to use the way out to establish a joint training system outside the school. Universities can send medical English teacher of the school to carry out good teaching learning from domestic and foreign colleges and universities, or to the medical unit, teaching foreign language education research institutions to study or to visit the exchange, broaden the horizons of teachers, teaching methods and learning foreign advanced methods, comprehensive teachers of English Majors of higher medical teaching ability and comprehensive quality. The third is to invite the experts and scholars from different universities, foreign language teaching experts and foreign counterparts to host seminars or forums in order to provide training and guidance for teaching theories and research methods, and provide the latest medical English information.

2. To perfect the system of teaching management and adhere to the system of teaching supervision

The perfection of teaching management system is a powerful guarantee for ensuring the quality of teaching and achieving the goal of personnel training. Its scientificity, rationality and normalization will have a significant impact on the whole process of teaching management. Teaching management system is an important factor for a series of teaching measures to be carried out smoothly. Therefore, it is necessary to consider all aspects of its factors and not blindly copy other units' rules and regulations, and combine their own teacher resources, hardware facilities and student quality. The development of teaching management and improvement of the system should be based on the concept of "training for the students, education for the students", the staff and students to participate in the development and perfection, we must pay attention to teaching management and students and listen to their views and opinions, fully mobilize the enthusiasm of the teachers focus on teaching enthusiasm and students' learning autonomy. Respect and protect the autonomy and creativity of teachers and students. We must adhere to the reform and innovation of teaching management system, adjust curriculum settings, teaching means and assessment methods according to the training objectives of compound talents, establish and improve the evaluation and supervision mechanism, and constantly improve the quality of teaching. The implementation of the system is more important than the formulation. A perfect teaching management system needs the common execution of all the teachers and students to ensure the smooth implementation of the personnel training. Therefore, the relevant teaching units should conscientiously implement the teaching management system, so that it can not become a mere scrap of paper (Zhou \& Cao, 2013). At the same time, we should set the system to implement, make the teaching management rules for all aspects of comprehensive, take full control of the teaching process, ensure the teaching adapting to the school's standards, effectively guarantee the teaching management mechanism and improve the quality of teaching.

3. To improve the teaching conditions and create a good learning atmosphere

School teaching facilities complete degree is directly related to the quality of teaching and training students. After entering the University, students' learning content in classroom is far from enough to meet their needs. A large amount of extracurricular resources can help students deepen their learning and understand related knowledge in other disciplines. At the same time, the diversified means of classroom teaching will also arouse the students' interest in learning. Therefore, it is imperative to increase the input of teaching resources and equipment. We need to update multimedia devices to meet the needs of classes, expand libraries and electronic reading rooms, and constantly update books, so that teachers and students can understand the progress of Frontier Medical Information in time. At the same time, in order to meet the needs of modern medical education, we should strengthen the construction of laboratories, classroom and multimedia classrooms, and improve the comprehensive quality of students with modern teaching techniques and means. With the increasing number of students, the living environment of students should be further 
improved and matched, and the life management system should be perfected to ensure that students learn in a comfortable and safe environment.

\section{To Set up and Perfect the Practice Base and Set up an Internship System}

The training of ability can not be confined to simple classroom teaching. In KAQ mode, the ability training requires students to improve their abilities both inside and outside class, and at the same time, promote the combination of knowledge and society. Practice as a link of students' training, it is an important way to internalize knowledge, enhance ability and improve quality, and is an important opportunity for learning and training before entering the society. It provides a good knowledge examination place. As an English for special purpose, medical English is a specialized and practical subject. It needs to be tested and consolidated in practice. In practice, we should pay attention to professional characteristics, choose professional counterparts or positions as practice units, provide practical opportunities for combining professional knowledge with practical problems, and integrate Book theoretical knowledge into practical work. In practice, we will encounter some problems that we haven't met before, or we can't learn from books or apply advanced knowledge, but these problems will enrich or modify the viewpoints in books, enrich and improve our knowledge structure. According to the survey, a medical university has no counterpart of the practice base, and the students are facing severe employment pressure and study and misunderstanding of the practice, lead to poor participation and enthusiasm in students, leading to the failure to fully exercise the ability of social practice, so that in the formal work competency is poor. Therefore, to guarantee the effect of internship, we first need to build an internship or practice base for medical English majors, enrich the diversity of practice units, and break the restrictions of past professional practice contents and management, so as to reduce students' passive practice. The basic coverage of students' employment coverage is relatively wide, and students can also find their own internship units according to their own characteristics and employment intentions. Secondly, to establish and improve the practice system, including the management system and the assessment system. The college should carry out the whole process of student internship throughout the whole process of student internship, internship time, internship content and practice discipline, strengthen the supervision of student teachers, and eliminate the phenomenon of going through the motions and cheating. In order to ensure the quality of students' practice, there must be the examination system, after the end of the internship, internship for students to carry out a full range of understanding, evaluation of training results, rewards and punishments (Zhu \& Kui, 2012).

\section{E. To Construct a Diversified System of Student Evaluation}

The evaluation system plays an important role in the process of personnel training. Effective evaluation system can not only test teachers' teaching results and test students' learning outcomes, but also better stimulate students' learning enthusiasm. According to the survey, a medical university English professional examination by using the traditional theory based assessment, students only learn from books, students generally lack of innovation ability and strain capacity. In order to improve the students' learning enthusiasm, the evaluation system of students' learning results should also be diversified. In addition to the traditional theory of theoretical examination and evaluation, the proportion of comprehensive evaluation can be increased and individualized evaluation is added to the students. According to the training objectives of the professionals and the characteristics of the students, we can carry out the second classroom activities, such as English Drama Festival, medical English Translation Contest and other special activities to encourage students to actively participate in, and for outstanding students in recognition of academic achievement evaluation, as in addition to outside scholarships and other awards of the comprehensive ability evaluation index in order to promote the development of students' comprehensive multi-level.

In addition, to establish a talent tracking mechanism to assess the effectiveness of training for graduates in school. As a newly emerging specialty with limited time and lack of relevant experience, we should keep abreast of the trend of graduates majoring in medical English and understand their social adaptability and social participation. To establish a complete tracking mechanism of talents according to their jobs in the dynamic behavior, further revision of medical English professional training objectives, clear professional training concept, perfect curriculum system, improve teaching methods, optimize the training mode of talents training in medical English, with English and more full of medical knowledge, medical English talents comprehensive strong practical ability and high quality. Personnel training mode to a certain extent determines students' competency, reaction mode of talent cultivation effect of graduate students competency level to a certain extent, through the understanding of graduates can promote the talent training mode of the dynamic improvement, so as to promote students' competency improving, develop circular development mode to optimize talent.

\section{CONCLUSION}

To sum up, English Majors in medical colleges and universities are important bridges to communicate with each other in the field of medicine, which will directly relate to the development of Medical Science in China. At present, medical English majors have been set up in many medical colleges and universities in China. At the same time, the training mode of medical English talents which are suitable for each other is also put forward. Medical English professional personnel training mode of talents training mode based on KAQ. With the internal and external 
requirements of talents of English medical professional development, it can develop a more complete English medical knowledge and talents, strong practical ability and high comprehensive quality, promoting the development of domestic medical industry. It plays an important role in the international academic medicine the exchange, and meets the needs of social development. English medical professional training talents meet the needs of social development, with the continuous optimization of talents training model of medical English. It is bound to promote the emergence of a large number of Chinese medicine and the world medical related personnel, so as to further improve China's pharmaceutical development level. It provides theoretical and practical experience for the establishment of an extrovert, compound and applied English major training system in the future.

\section{REFERENCES}

[1] Cheng, S. \& J.W. Zheng. (2012). "A Preliminary Discussion on Reforming Medical English Teaching Methods.” Journal of Medical Education in Northwest China 20 (5): 985-987.

[2] Li, F. P. (2014). An Exploration of Medical English Teaching Reform in Higher Medical Colleges from the Perspective of Theory. Jiangxi: Jiangxi people's Publishing House.

[3] Li, X. W. \& D. L. Xu. (2015). "An Exploration of English Curriculum in Medical Colleges and Universities from the Perspective of ESP." Journal of Continuing Medical Education 29 (1): 41-43.

[4] Liu, Y. H. \& P. Li. (2013). "How to Cultivate Students' Ability to Learn Medical English from the Characteristics of Medical English?" Yibin Health School (16): 55-56.

[5] Ma, S. M. (2011). "The Curriculum Reform and Teaching Content Reform for English Majors in Medical Colleges." Journal of Medical Education in Northwest China 19 (2):355-358.

[6] Mou, D. M. \& Y. X. Zhang. (2013). “A Research on Teaching System of Health Management Information System Based on KAQ." Journal of Higher Medical Education in China (08):77-78.

[7] Wang, G. L. (2014). "ESP or EGP? The Students' Perceptions towards Medical English Teaching in General Medical Colleges." Journal of Medical Education Technology in China 28 (2):215-220.

[8] Wang, T. (2014). "Some Enlightenments of American Medical Humanities Education to Medical English Teaching in Medical Colleges and Universities in China." Journal of Continuing Medical Education 28 (7): 100-103.

[9] Wang, Y. Z. \& J. Ni. (2012). "A Discussion on KAQ Training Mode of Pharmaceutical Management Applied Talents in Chinese Pharmacy.” Qilu Pharmaceutical Affairs (08): 490-491.

[10] Zhang, Y. \& Q. Zhao. (2014). "A Research on KAQ Talent Training Mode of Medical Information Engineering Specialty." Journal of Medical Education Technology in China (05): 488-491.

[11] Zhou, N. N. \& J. D. Cao. (2013). "Discussion and Practice of KAQ Training for Medical Informatics Postgraduates." Journal of Higher Medical Education in China (11): 116-117.

[12] Zhu, W. J. \& X. L. Kui. (2012). "Strengthening the Consciousness of Professional Positioning for Medical English Majors." Acta Academiae Medicinae Neimongol 34(4): 604-606.

Yuan Kong received her M.A. degree in linguistics. She is currently a lecturer at the School of Foreign Languages, Jining Medical University, Jining, Shandong, China. She teaches various subjects including: English intensive reading, English extensive reading, listening, nursing reading and so on. Her research interests mainly include English language teaching, applied linguistics, cross-cultural communication, etc. 